\title{
Association of Serum Calcium and Vitamin D with Benign Paroxysmal Positional Vertigo
}

\author{
Ron Jacob Thomas ${ }^{1} \quad$ M. K. Goutham ${ }^{1}$ Vadisha Srinivas Bhat ${ }^{10}$ Shrinath D. Kamath ${ }^{1}$ \\ Rajeshwary Aroor $^{1}$ Satheesh Kumar Bhandary ${ }^{1}$ \\ 1 Department of Otorhinolaryngology, K S Hegde Medical Academy, \\ Nitte (Deemed to be University), Mangalore, Karnataka, India \\ Int Arch Otorhinolaryngol 2022;26(3):e365-e369. \\ Address for correspondence Vadisha Srinivas Bhat, MS(ENT), DNB \\ (ENT), Department of Otorhinolaryngology, K S Hegde Medical \\ Academy, Mangalore, Karnataka, 575018, India \\ (e-mail: bvadish@yahoo.co.in).
}

\section{Introduction}

Benign paroxysmal positional vertigo (BPPV) is considered the most common cause of vertigo. It is characterized by recurring attacks of vertigo when the head is placed in a particular critical position. ${ }^{1}$ The mechanism of BPPV is explained by the otoconial displacement to the semicircular canals (SCCs) from the utricle, secondary to the degeneration of the vestibular system involving the otoliths. Among the various factors that lead to the damage and dislodgement of

received

July 26, 2020

accepted after revision

November 21, 2020

published online

November 3, 2021
DOI https://doi.org/ 10.1055/s-0041-1724093. ISSN 1809-9777. the otoconia are labyrinthitis and head trauma; the exact etiology of BPPV remains unidentified in most cases. ${ }^{2}$

Benign paroxysmal positional vertigo can be observed in any age group, but a higher incidence of BPPV has been reported in the elderly population. Idiopathic BPPV has been linked to general diseases like diabetes, ${ }^{3}$ chronic thyroiditis, ${ }^{4}$ hypertension, hyperlipidemia, stroke, ${ }^{4}$ osteoporosis/osteopenia, ${ }^{5}$ and vitamin D deficiency. ${ }^{6}$ Among these, the association of BPPV with vitamin D deficiency and osteoporosis implies that deranged calcium metabolism may be underlying BPPV. (c) 2021. Fundação Otorrinolaringologia. All rights reserved.

This is an open access article published by Thieme under the terms of the Creative Commons Attribution-NonDerivative-NonCommercial-License, permitting copying and reproduction so long as the original work is given appropriate credit. Contents may not be used for commercial purposes, or adapted, remixed, transformed or built upon. (https://creativecommons.org/ licenses/by-nc-nd/4.0/)

Thieme Revinter Publicações Ltda., Rua do Matoso 170, Rio de Janeiro, RJ, CEP 20270-135, Brazil 
The present study aimed to estimate serum levels of calcium and vitamin D in patients with BPPV and to study if there was any association between them and BBPV.

\section{Methods}

The present is a prospective study performed in the tertiary care hospital of our institution between January 2018 and June 2019. Approval by the institutional ethics committee was obtained. Patients with clinical features of positional vertigo were evaluated with the positional maneuver. Those patients with a positive result on positional maneuvers were included in the study with written informed consent. Patients on vitamin D or calcium supplementation, for any reason, were excluded from the study. With particular emphasis on the number of episodes of positional vertigo, their history was recorded, followed by a thorough ear, nose and throat (ENT) examination. Venous blood samples were collected and analyzed for serum calcium using automated standard laboratory methods. The analysis of the serum levels of vitamin D (25-hydroxyvitamin D) was performed using a radioimmunoassay test with the cobas e 411 analyzer (Roche, Basel, Switzerland). The control group was composed of age- and gender-matched healthy individuals from the same geographical area, not on calcium or vitamin D supplementation for any other reason. The serum levels of calcium and vitamin $\mathrm{D}$ of the controls were estimated after we obtained the written informed consent.

Quantitative variables, such as age and serum levels of calcium and vitamin D are expressed as means and standard deviations. Qualitative data, such as gender, type of BPPV (posterior, horizontal, and anterior) are expressed as percentages and proportions. The Chi-squared test was used to assess the degree of association. The odds of the disease among the exposed were calculated as discordant pairs (b/c), with a 95\% confidence interval $(95 \% \mathrm{CI})$. The Statistical Package for the Social Sciences (SPSS, IBM Corp., Armonk, NY, US) software, version 22.0, was used to analyze the collected data. Values of $p<0.05$ were considered statistically significant. The Pearson correlation was used to assess the association between the serum levels of vitamin D and the number of episodes of BPPV.

\section{Results}

The present study included 49 cases of BPPV and an equal number of age- and gender-matched controls. There was a female preponderance; $67.3 \%$ of the sample were composed of female patients, and $32.7 \%$ were males. This ratio was maintained during the selection of the control group. The youngest patient in our study was 21 years old, and the oldest was 74 years old. Most of the cases were in the age group of 41 to 50 years; 16 patients (32.7\%) were in this group. The mean age of the cases in our study was 44.39 years.

Most of the cases (49\%) had experienced 4 to 6 episodes of positional vertigo before enrolling in the study; $22.5 \%$ had more than 6 episodes. The maximum number of episodes recorded among the cases was 15 , and the minimum was 1 (-Table 1).
Table 1 Number of episodes among the study sample

\begin{tabular}{|l|l|l|}
\hline Number of episodes & Cases $(\boldsymbol{n}=\mathbf{4 9})$ & Percentage \\
\hline $1-3$ & 14 & $28.5 \%$ \\
\hline $4-6$ & 24 & $49 \%$ \\
\hline$>6$ & 11 & $22.5 \%$ \\
\hline
\end{tabular}

The clinical diagnosis was made by performing positional maneuvers. The Dix-Hallpike maneuver was found to be positive in all the patients in the present study, indicating the involvement of the posterior SCC. Among the 49 cases, 31 (63.3\%) had left-sided BPPV, and 17 (34.7\%) had right-sided BPPV. Only 1 (2.04\%) out of the 49 cases had bilateral BPPV.

The mean serum level of vitamin D among the cases was of $21.2 \mathrm{ng} / \mathrm{ml}$, and, among the controls, it was of $17.5 \mathrm{ng} / \mathrm{ml}$. However, the statistical analysis did not show any significance $(p=0.243)$.

According to the serum levels of vitamin D, the cases and controls were further categorized into 3 subgroups. Group 1: vitamin $\mathrm{D} \leq 10 \mathrm{ng} / \mathrm{ml}$; group 2: vitamin $\mathrm{D} \geq 11 \mathrm{ng} / \mathrm{ml}$ and $\leq 30 \mathrm{ng} / \mathrm{ml}$; and group 3 (optimum): vitamin $\mathrm{D} \geq 31 \mathrm{ng} / \mathrm{ml}$.

Among the cases, 7 (14.28\%: 4 male; 3 female) were in group 3; 40 (81.63\%: 11 male; 29 female) were in group 2; and 2 (4.08\%: 1 male; 1 female) were in group 1 (-Table 2 ).

Among the 49 controls, 6 (12.24\%; 2 male and 4 female) were in group $3 ; 37$ (75.51\%; 13 male and 24 female) were in group 2; and 6 (12.24\%; 1 male; 5 female) were in group 1.

Low serum levels of vitamin $\mathrm{D}(<30 \mathrm{ng} / \mathrm{ml})$ were observed in $42(85.7 \%)$ of the cases and in $43(87.8 \%)$ of the controls. The mean serum level of vitamin $\mathrm{D}$ level in the cases was of $21.26 \mathrm{ng} / \mathrm{ml}$, and of $17.59 \mathrm{ng} / \mathrm{ml}$ in the controls (-Table 3 ). However, there was no statistically significant association between the srum levels of vitamin D and BPPV among the cases or controls $(p=0.243)$.

There was a negative correlation between the serum levels of vitamin D and the number of BPPV episodes, suggesting that people with lower levels had more episodes (Pearson correlation; $\mathrm{r}=-0.357$ ).

The mean serum level of calcium among the cases was of $9.337 \mathrm{mg} / \mathrm{dl}$, and among the controls, it was of $8.955 \mathrm{mg} / \mathrm{dl}$ (-Table 4). The statistical analysis did not show any significance between the serum levels of calcium and BPPV $(p=0.976)$.

\section{Discussion}

Vertigo is a sensation that the environment is spinning, indicating a lesion within the vestibular system that can be either central or peripheral. ${ }^{7}$ Among all the peripheral vestibular disorders that cause vertigo, BPPV is the most common $^{8}$ peripheral vestibular disease, contributing to $12 \%$ to $51 \%$ of the cases of vertigo in the clinical practice, according to studies in different geographical areas. ${ }^{9,10}$

In the present study, we included 49 clinically-diagnosed cases of BPPV and 49 controls who were age- and gendermatched healthy individuals. There was a preponderance of female patients among the cases, with 33(67.3\%) female 
Table 2 Numbers of cases and controls regarding serum levels of vitamin D

\begin{tabular}{|l|l|l|l|l|l|l|}
\hline \multirow{2}{*}{$\begin{array}{l}\text { Serum level of vitamin D } \\
(\mathbf{n g} / \mathrm{mL})\end{array}$} & \multicolumn{4}{|l|}{ Cases $(\boldsymbol{n}=\mathbf{4 9})$} & \multicolumn{2}{l|}{ Controls $(\boldsymbol{n}=\mathbf{4 9})$} \\
\cline { 2 - 7 } & Male & Female & Total & Male & Female & Total \\
\hline$<10$ & 1 & 1 & 2 & 1 & 5 & 6 \\
\hline $11-30$ & 11 & 29 & 40 & 13 & 24 & 37 \\
\hline$>30$ (optimal) & 4 & 3 & 7 & 2 & 4 & 6 \\
\hline
\end{tabular}

Table 3 Serum levels of vitamin $D(\mathrm{ng} / \mathrm{mL})$ in the cases and controls

\begin{tabular}{|l|l|l|l|l|l|}
\hline \multirow{2}{*}{} & Mean & Standard deviation & \multicolumn{2}{|l|}{$\begin{array}{l}\text { 95\% confidence interval } \\
\text { for the mean }\end{array}$} & \multirow{2}{*}{-value on the $t$-test } \\
\cline { 4 - 5 } & & & Lower bound & Upper bound & \\
\hline Cases $(n=49)$ & 21.2639 & 0.56718 & 18.5159 & 24.0119 & 0.243 \\
\hline Controls $(n=49)$ & 17.5906 & 0.06099 & 15.2752 & 19.9060 & \\
\hline
\end{tabular}

Table 4 Serum levels of calcium $(\mathrm{mg} / \mathrm{dL})$ in the cases and controls

\begin{tabular}{|l|l|l|l|l|l|}
\hline & Mean & Standard deviation & \multicolumn{2}{l|}{$\begin{array}{l}\text { 95\% confidence interval } \\
\text { for the mean }\end{array}$} & \multirow{2}{*}{-value on the $t$-test } \\
\cline { 4 - 6 } & & & Lower bound & Upper bound & \\
\hline Cases $(n=49)$ & 9.337 & 0.5525 & 9.178 & 9.495 & 0.976 \\
\hline Controls $(n=49)$ & 8.955 & 0.8193 & 8.720 & 9.190 & \\
\hline
\end{tabular}

patients, and $16(32.7 \%)$ male patients. This was in line with a previous study, ${ }^{11}$ which reported that BPPV is common among females.

In the present study, the youngest patient was 21 years old, and the oldest was 74 years old. The mean age of the patients in our study was 44.39 years. This observation is in line with past researches, ${ }^{11,12}$ which indicated that BPPV is not a common disease among the younger age group.

Benign paroxysmal positional vertigo has been found more frequently among women older than 50 years of age than in younger women. One of the causes of this may be the hormonal changes due to menopause, which influence calcium metabolism. ${ }^{13}$ This could be because of the degeneration of the otoconia due to altered calcium metabolism, which facilitates their dislocation. ${ }^{14}$

Benign paroxysmal positional vertigo can result either due to canalithiasis or cupulolithiasis, and it can affect any of the three SCCs. In the present study, all the cases had involvement of the posterior SCC. This may be attributed to the fact that canalithiasis most frequently involves the posterior SCC as it is the most dependent canal. ${ }^{15}$

The involvement of the posterior SCC has been reported as the most common, followed by the lateral semicircular canal and anterior SCCs. Thoug rare, tere may be a combinations of posterior and lateral SCCs. ${ }^{11}$

There is no unanimity regarding the laterality of BPPV, as few studies reported the disease to be common on the right side, while the others, on the left side. ${ }^{8,16}$ In the present research, we found that among the 49 cases, 48 (97.9\%) had unilateral BPPV. The left side was more commonly affected
(31 cases - 63.3\%) compared with the right side. In the present study, only 1 out of the 49 cases (2.04\%) had bilateral involvement of the posterior SCCs, a rare phenomenon accounting for less than $10 \%$ of the cases according to literature. ${ }^{17}$ Bilateral involvement of SCCs is frequently seen following a head injury. ${ }^{8}$ However, our patient did not have any such history of head trauma.

Different studies have demonstrated the relationship between bone metabolism and BPPV. ${ }^{6,11}$ Studies have shown a similar relationship between the otoconia and bone biomineralization; the organization of the matrix is identical in the two tissues, 5,18 and they share the majority of the constituents of the proteins. Like the teeth and bones, the biomineralization of the otoconia involvesa tight regulation of the organic matrix formation at specific sites, and the deposition of mineral crystallites in an orderly manner. ${ }^{18}$ The evidence that favors the relationship between deranged calcium metabolism and BPPV are: reduced bone mineral density is more commonly observed in BPPV patients than in healthy controls; estrogen deficiency causing otoconia degeneration and development of BPPV; reduced levels of vitamin D associated with the development of BPPV; and supplementation of vitamin D and calcium lowering the episodes of BPPV. ${ }^{6}$

The mean serum level of vitamin $D$ in the present study was of $21.26 \mathrm{ng} / \mathrm{mL}$ among the cases compared, with $17.59 \mathrm{ng} / \mathrm{mL}$ in the control group; however, there was no correlation between these levels and BPPV, as both the cases and controls had almost comparable mean serum levels of vitamin D $(p=0.243)$. 
A few earlier studies correlated the serum levels of vitamin D and calcium with BPPV, with a hypothesis of a higher prevalence of BPPV among people with low levels of vitamin D. Cikrikci et al. ${ }^{19}$ determined the median serum levels of vitamin D among BPPV patients and healthy controls to be of $9.51 \mathrm{ng} / \mathrm{ml}$ and $7.8 \mathrm{ng} / \mathrm{ml}$ respectively, but did not find any statistical significance between the cases and controls $(p=0.99)$. In the same study, the median total serum level of calcium was of $9.5 \mathrm{mg} / \mathrm{dl}$ among the cases, and of $9.43 \mathrm{mg} / \mathrm{dl}$ in the control group, with no statistically significant difference between the two groups $(r=0.34)$. They could not ascertain a significant relationship between the serum levels of vitamin D and calcium in both groups $(p>0.05)$, and were also unable to establish a statistically significant correlation between vitamin $\mathrm{D}$ and calcium levels among the cases and controls.

In the present study, we established a negative correlation between serum levels of vitamin D and episodes of BPPV. A few studies have shown that vitamin D deficiency and insufficiency are associated with increased BPPV episodes. $^{20,21}$ There is evidence suggesting an improvement in the recurrences of BPPV after the correction of the vitamin D deficiency. ${ }^{16}$

Vitamin D levels are influenced by age and seasonal factors, apart from several other factors like gender, dressing habits, skin color, diet, body mass index, and supplements. ${ }^{22}$ In the present research, most of the cases and controls were female, and the mean age was also higher. These could be the reasons why vitamin $\mathrm{D}$ was found to be low in both cases and controls in the present study.

Vitamin D is known to influence calcium metabolism. However, researchers ${ }^{5}$ could not establish any association between the serum levels of calcium and BPPV. This relationship was also assessed in the present study, and we could not find any significant difference in the total levels of calcium of the cases and controls.

Recurrence of BPPV is a frequently encountered problem. A significantly higher recurrence is observed among patients with osteoporosis as compared with patients with normal bone mass. The decrease in bone mineral density is associated with an increase in the frequency of BPPV recurrence, especially among middle-aged women. ${ }^{23,24}$

\section{Conclusion}

We concluded that BPPV mainly affects women, and it is a disease of the older-age group. The results of the present study showed that the serum levels of vitamin D were generally low among the study population. No correlation was established between the serum levels of calcium and vitamin D with BPPV. This may be because of the overall lower serum levels of vitamin $\mathrm{D}$ among the general population in this geographical area. However, a negative correlation was established between the serum levels of vitamin D and several BPPV episodes, which was statistically significant, suggesting that, as the levels of vitamin $\mathrm{D}$ decrease, there are more chances of recurrence of BPPV.

\section{Limitations of the Study}

The sample size is small to derive a definite conclusion, considering the prevalence of BPPV. A study with a large sample is recommended. The control group was selected based only on the history of absence of vertigo. We did not perform any clinical evaluation or positional maneuvers on the controls, which may have led us to miss unrecognized cases of BPPV. The seasonality of BPPV, which could have affected the its presentation, was not recorded. We did not study the bone mineral density, which could be a better parameter than the serum levels of vitamin $D$ and calcium. As the relationship between vitamin D and BPPV is complex, a causal association can be established with a systematic study in different geographical regions.

Conflict of Interests

The authors have no conflict of intersts to declare.

\section{References}

1 Kim JS, Zee DS. Clinical practice. Benign paroxysmal positional vertigo. N Engl J Med 2014;370(12):1138-1147

2 Baloh RW, Honrubia V, Jacobson K. Benign positional vertigo: clinical and oculographic features in 240 cases. Neurology 1987; 37(03):371-378

3 Cohen HS, Kimball KT, Stewart MG. Benign paroxysmal positional vertigo and comorbid conditions. ORL J Otorhinolaryngol Relat Spec 2004;66(01):11-15

4 von Brevern M, Radtke A, Lezius F, et al. Epidemiology of benign paroxysmal positional vertigo: a population based study. J Neurol Neurosurg Psychiatry 2007;78(07):710-715

5 Parham K, Leonard G, Feinn RS, Lafreniere D, Kenny AM. Prospective clinical investigation of the relationship between idiopathic benign paroxysmal positional vertigo and bone turnover: a pilot study. Laryngoscope 2013;123(11):2834-2839

6 Jeong SH, Kim JS, Shin JW, et al. Decreased serum vitamin D in idiopathic benign paroxysmal positional vertigo. J Neurol 2013; 260(03):832-838

7 Brandt T. Background, technique, interpretation, and usefulness of positional and positioning testing. In: Jacobson GP, Newman CW, Kartush JM, (ed). Handbook of balance function testing. I ${ }^{\text {st }}$ ed. 1997DelmarNew York

8 Katsarkas A. Benign paroxysmal positional vertigo (BPPV): idiopathic versus post-traumatic. Acta Otolaryngol 1999;119(07): 745-749

9 Sarkar A, Sen K, Raghavan A. The vertigo spectrum: A retrospective analysis in 149 walk-in patients at a specialized neurotology clinic. Astrocyte 2016;3(01):12

10 Drachman DA, Hart CW. An approach to the dizzy patient. Neurology 1972;22(04):323-334

11 Sen K, Padiyar B, Arora G. Association of Benign Paroxysmal Positional Vertigo with Osteoporosis and Vitamin D Deficiency - A Case-Control Study. Dubai Medical Journal. 2018;1(1-4):2-5

12 Caldas MA, Ganança CF, Ganança FF, Ganança MM, Caovilla HH. Clinical features of benign paroxysmal positional vertigo. Rev Bras Otorrinolaringol (Engl Ed) 2009;75(04):502-506

13 Barber HO. Positional nystagmus, especially after head injury. Laryngoscope 1964;74:891-944

14 Yang L, Xu Y, Zhang Y, Vijayakumar S, Jones SM, Lundberg YYW. Mechanism Underlying the Effects of Estrogen Deficiency on Otoconia. J Assoc Res Otolaryngol 2018;19(04):353-362

15 Harvey SA, Wood DJ, Feroah TR. Relationship of the head impulse test and head-shake nystagmus in reference to caloric testing. Am J Otol 1997;18(02):207-213 
16 Büki B, Ecker M, Jünger H, Lundberg YW. Vitamin D deficiency and benign paroxysmal positioning vertigo. Med Hypotheses 2013;80 (02):201-204

17 Yacovino DA, Hain TC, Gualtieri F. New therapeutic maneuver for anterior canal benign paroxysmal positional vertigo. J Neurol 2009;256(11):1851-1855

18 Yang $\mathrm{H}$, Zhao X, Xu Y, Wang L, He Q, Lundberg YW. Matrix recruitment and calcium sequestration for spatial specific otoconia development. PLoS One 2011;6(05):e20498

19 Cikrikci Isik G, Cevik Y, Emektar E, et al. Analysis of Vitamin D and Calcium Levels in Benign Paroxysmal Positional Vertigo. Eurasian Journal of Emergency Medicine. 2017;16(03):128-132

20 Talaat HS, Kabel AM, Khaliel LH, Abuhadied G, El-Naga HA, Talaat AS. Reduction of recurrence rate of benign paroxysmal positional vertigo by treatment of severe vitamin D deficiency. Auris Nasus Larynx 2016;43(03):237-241
21 Sheikhzadeh M, Lotfi Y, Mousavi A, Heidari B, Monadi M, Bakhshi E. Influence of supplemental vitamin $D$ on intensity of benign paroxysmal positional vertigo: A longitudinal clinical study. Caspian J Intern Med 2016;7(02):93-98

22 Honrubia V, Hoffman LF. 1997Practical anatomy and physiology of the vestibular system. In: Jacobson GP, Shepard NT, (eds) Balance Function Assessment and Management. San Diego: Plural Publishing; 9-52

23 Jang YS, Kang MK. Relationship between bone mineral density and clinical features in women with idiopathic benign paroxysmal positional vertigo. Otol Neurotol 2009;30(01): 95-100

24 Jeong SH, Choi SH, Kim JY, Koo JW, Kim HJ, Kim JS. Osteopenia and osteoporosis in idiopathic benign positional vertigo. Neurology 2009;72(12):1069-1076 